\title{
Estudo dos efeitos da carbonatação na vida útil de pontes de concreto armado
}

A busca por maior rapidez e economia na construção civil tem gerado erros de execuções e projetos, especificação de materiais inadequados, mão de obra desqualificada e diferentes tipos de patologias. O estudo cuidadoso dos problemas a partir das características e manifestações patológicas permite um conhecimento mais aprofundado de suas causas. Sendo assim, o presente estudo de caso tem como foco a análise da dureza superficial e da profundidade de carbonatação do concreto dos pilares da ponte localizado na cidade de Porto Nacional/TO, construída com a criação do lago na cidade. Faz parte desse estudo também uma breve analise patológica visual, que teve como intuito uma avaliação qualitativa. Através de ensaio não-destrutivo (esclerometria) e ensaio semidestrutivo (medição da profundidade de carbonatação in loco), obtiveram-se valores de índices esclerométricos que se correlacionaram com a profundidade de carbonatação e resistência à compressão do concreto, permitindo estimar a vida útil dos pilares da ponte.

Palavras-chave: Concreto Armado; Pontes; Esclerometria; Carbonatação.

\section{Study of the effects of carbonating on the useful life of armed reinforced concrete}

The search for greater speed and economy in construction has generated errors in executions and projects, specification of inappropriate materials, disqualified labor and different types of pathologies. The careful study of the problems from the characteristics and pathological manifestations allows a deeper knowledge of its causes. Thus, the present case study focuses on the analysis of the surface hardness and depth of carbonation of the concrete of the bridge pillars located in the city of Porto Nacional / TO, built with the creation of the lake in the city. Also part of this study is a brief visual pathological analysis, whose purpose was a qualitative evaluation. Through non-destructive testing (sclerometry) and semi-destructive testing (measurement of the carbonation depth in loco), sclerometric indices were obtained that correlated with the depth of carbonation and compressive strength of the concrete, allowing to estimate the useful life of the bridge pillars.

Keywords: Reinforced concrete; Bridges; Sclerometry; Carbonation.

Topic: Engenharia Civil

Reviewed anonymously in the process of blind peer
Received: 14/06/2018

Approved: 24/09/2018

Pamella Abreu de Sousa

Faculdade Presidente Antônio Carlos, Brasi http://lattes.cnpq.br/2261961813603853 pamella sousa8@hotmail.com

\section{Taís Gomes}

Faculdade Presidente Antônio Carlos, Brasi http://lattes.cnpq.br/4299624774874461 tais.go3@gmail.com

\section{Referencing this:}

SOUSA, P. A.; GOMES, T.. Estudo dos efeitos da carbonatação na vida útil de pontes de concreto armado. Engineering Sciences, v.6, n.2, p.111, 2018. DOI: http://doi.org/10.6008/CBPC2318-3055.2018.002.0001 


\section{INTRODUÇÃO}

As patologias das construções são citadas por Silva (2016), como o ramo da engenharia que estuda os sintomas, manifestações, origens e causas das 'doenças' que podem surgir nas edificações. $O$ termo patologia significa algum tipo de defeito em área ou algum material. Seria uma anomalia que foi causada por algum problema não previsto em projeto ou execução da obra, podendo atingir a estética ou até mesmo a segurança da construção.

Os estudos das manifestações patológicas são de grande importância, já que a edificação pode ficar com aparência desagradável, e agravando-se pode comprometer a estrutura. A diminuição de incidências de patologia reduz custos de operação e manutenção. Com o desenvolvimento de técnicas construtivas que vinham a atender à necessidade coletiva, a construção de pontes está intrínseca na história da humanidade, e o aprimoramento deste tipo de construção especial ainda é constante para que seja cada vez mais garantida a sua funcionalidade e a segurança de quem a transita.

Com o aumento da urbanização e crescimento das cidades, Possan (2010) afirma que houve o aumento das emissões de $\mathrm{CO}_{2}$ na atmosfera, afetando as estruturas de concreto em ambiente urbano. Isso porque a profundidade de carbonatação aumenta com a concentração do $\mathrm{CO}_{2}$ no meio ambiente, afetando o ciclo de vida das estruturas e reduzindo a durabilidade das mesmas. Diante do exposto, o presente artigo busca realizar ensaios sobre a dureza superficial e da profundidade de carbonatação do concreto dos pilares na ponte localizada na cidade de Porto Nacional/TO.

A carbonatação é um processo físico-químico caracterizado pela formação de sais de carbonato pela reação de neutralização do hidróxido de cálcio $(\mathrm{CH})$ pelo gás carbônico $\left(\mathrm{CO}_{2}\right)$. Na fase aquosa dos poros, ocorre a dissolução do hidróxido de cálcio, formado nas reações de hidratação do cimento. Por difusão, o gás carbônico penetra no concreto e se desloca através da fase aquosa do poro da matriz, se dissolvendo na solução aquosa. Por fim, temos a reação entre o gás carbônico dissolvido e o hidróxido de cálcio $\left[\mathrm{Ca}(\mathrm{OH})_{2}\right]$ dissolvido, assim como com outros produtos carbonatáveis da pasta de cimento, formando carbonatos (CASCUDO et al., 2011).

Como o $\mathrm{CH}$ é a reserva alcalina responsável por manter o pH da pasta de cimento elevado (valores superiores a 12,5), caso seja consumido na reação de carbonatação, tem-se um efeito de redução do pH do concreto para valores inferiores a 8,3, e essa camada de concreto perde a capacidade de proteger quimicamente as barras de aço dos elementos estruturais (MEHTA et al., 2008). Quanto maior a concentração de gás carbônico no concreto, menor será seu pH, e maior será sua camada carbonatada.

A velocidade com que a frente de carbonatação avança depende tanto das condições de exposição, que influenciam na difusão do $\mathrm{CO}_{2}$, quanto das características do concreto, que influenciam na reserva alcalina disponível e no sistema de poros. Quanto maior o teor de $\mathrm{CO}_{2}$ no ambiente, maior será a carbonatação. A carbonatação cresce também com o aumento da temperatura ambiente. Acréscimos de temperatura aumentam a mobilidade das espécies iônicas, aumentando a velocidade das reações químicas. A umidade relativa do ambiente influi na quantidade de água presente nos poros, a qual governa a velocidade 
de difusão dos gases. Poros saturados (100\%) causam baixa velocidade de difusão e em poros com umidade<25\% não há água insuficiente para as reações (BERTOLLINI, 2010). Várias são as técnicas para se determinar a profundidade de carbonatação, embora haja diferença nos valores medidos entre os procedimentos, o mais utilizado é o de indicadores de $\mathrm{pH}$, por isso nesse trabalho utilizou-se a fenolftaleína.

\section{METODOLOGIA}

O trabalho focou no estudo da ponte dentro do município de Porto Nacional/TO, levando em consideração que, após consulta aos órgãos públicos e a empresa responsável pelo projeto, nenhum projeto ou memorial descritivo foi disponibilizado. Foi construída com a construção da UHE - Lajeado, no Rio Tocantins, devido à criação do lago na cidade, por falta de informações, hipóteses foram levantadas ao longo do estudo. Com a construção da Usina Hidrelétrica em Lajeado por volta de 1998-2002 e a formação do lago na cidade, houve a necessidade da criação de pontes para integrar setores do município.

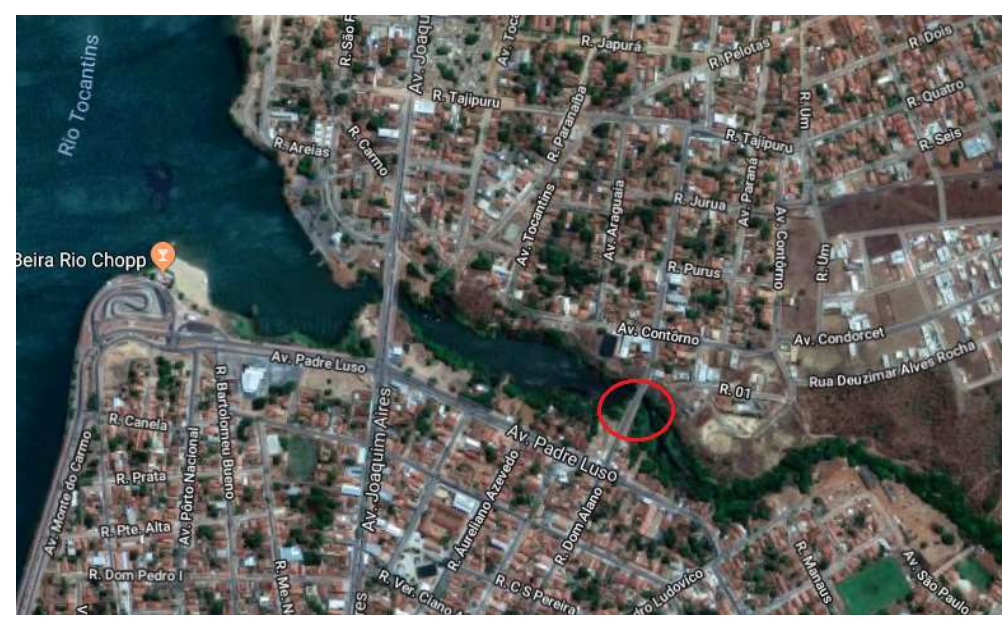

Figura 1: Localização da Ponte.

Através dos cortes apresentados nas Figuras 2 e 3 é possível analisar os pilares onde serão feitos os testes, pontos estes que têm uma relevância considerável para a estabilidade estrutural.

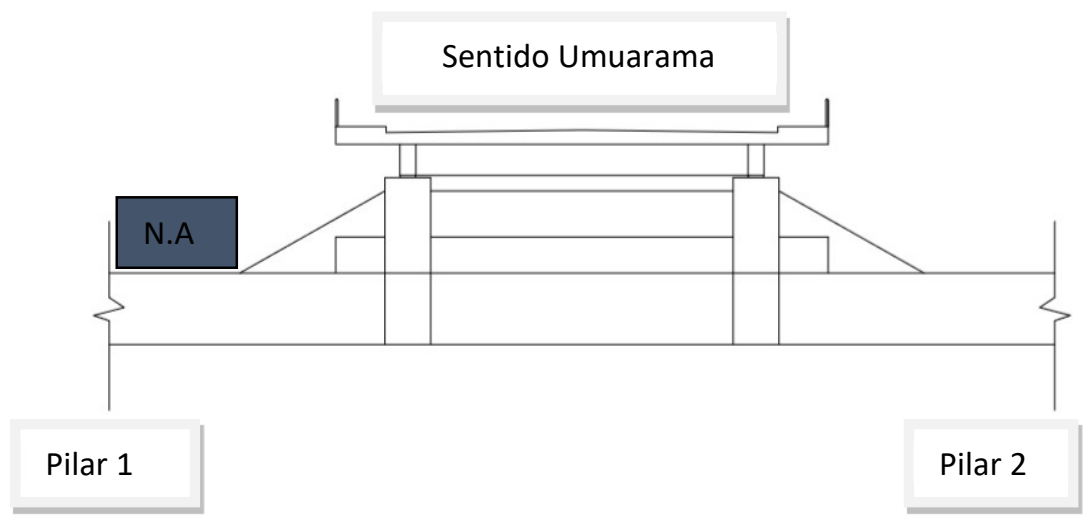

Figura 2: Corte Transversal da ponte. 


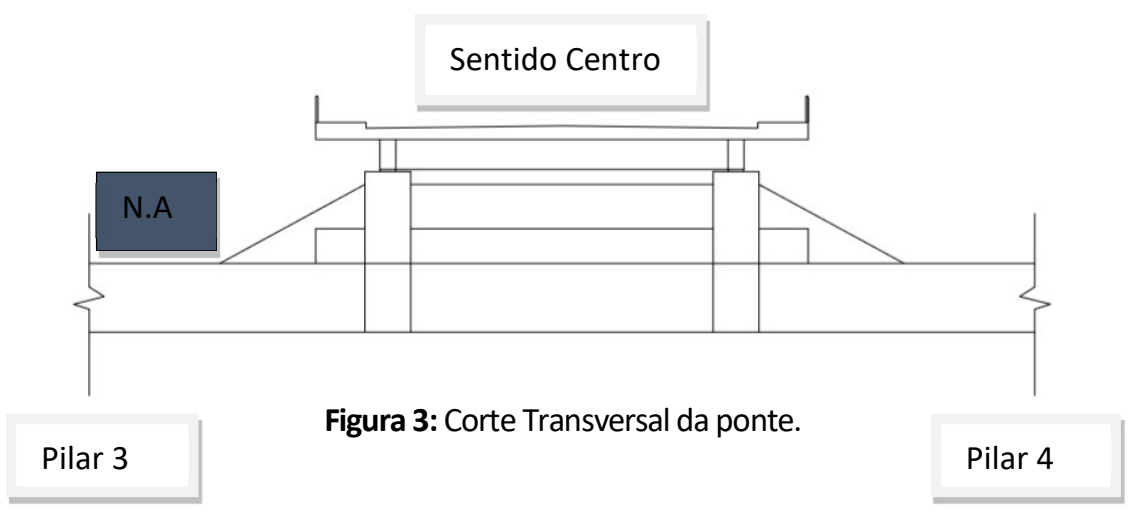

\section{Levantamento de dados: Investigação visual}

De acordo com a NBR 5674 (ABNT, 1999) as inspeções devem ser direcionadas por listas que tenham uma sequência lógica e padrão, que possa descrever a deterioração dos componentes do edifício avaliando a perda do seu desempenho, assim sendo a primeira etapa para avaliação das informações coletadas do problema proposto. As visitas técnicas foram realizadas com câmera fotográfica para registrar e posteriormente identificar e quantificar as patologias existentes na obra de arte especial, como não se tem o projeto original em mãos, obter as dimensões é um passo muito importante para o início do estudo de caso. Para efetuar uma medição da ponte, utilizou-se uma trena, medindo o vão das pontes, pilares e dimensões acessíveis.

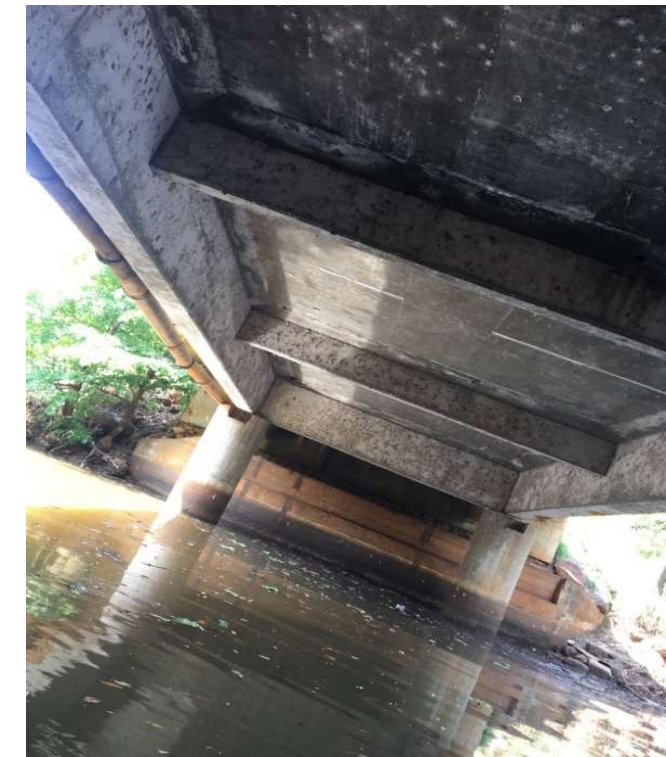

Figura 4: Inferior do Tabuleiro.

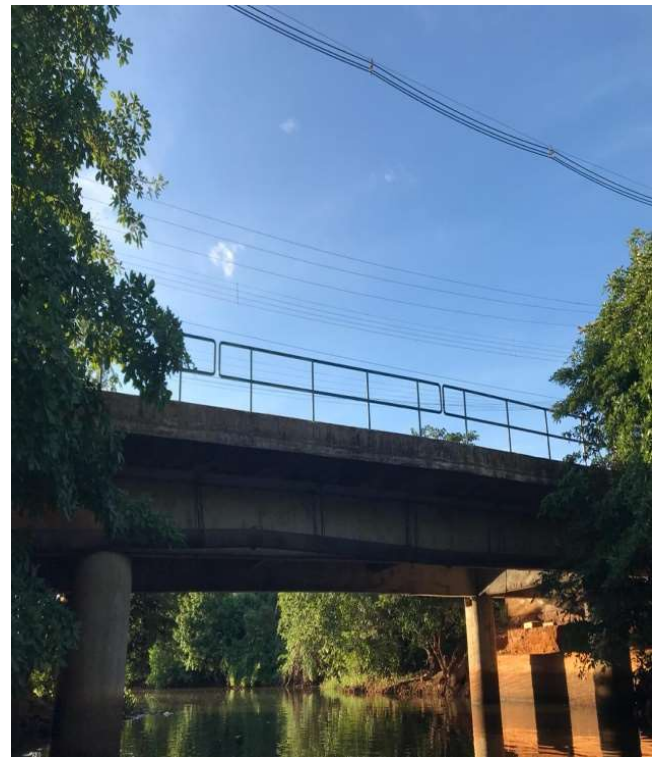

Figura 5: Vista Lateral.

\section{Medição da carbonatação do concreto}

O procedimento para o ensaio de medição da frente de carbonatação por fenolftaleína é feito por pontos de medição que deverão ser criteriosamente selecionados e as superfícies expostas aos agentes naturais deverão ser alvo de um número maior de medições. Os pontos selecionados deveram ser os mais críticos da estrutura. A profundidade dos furos ou cavidades deverá ser superior a mínimo de $1 \mathrm{~cm}$ ao recobrimento, podendo ser medido com o detector de armaduras. Deve ser feita a limpeza superficial correta do furo utilizando um pincel, não podendo ser realizado o ensaio em superfície serrada, molhada e com 
presença de pó, para que os resíduos de pó não interfiram no resultado. Com o borrifador, a solução de fenolftaleína é aplicada em forma de névoa, aplicando na superfície dos corpos-de-prova ou estruturas inspecionadas.

$\mathrm{O}$ indicador de $\mathrm{pH}$ escolhido para o ensaio foi a fenolftaleína, que é um ácido base indicador de $\mathrm{pH}$ com a seguinte fórmula: $\mathrm{C}_{20} \mathrm{H}_{14} \mathrm{O}_{4}$. $\mathrm{O}$ indicador para a medição de carbonatação provoca um contraste na coloração devido à redução de pH na frente de carbonatação. Se o pH estiver abaixo de 9, será observada uma área carbonatada incolor, se o pH for maior de 9, a solução de fenolftaleína terá uma coloração vermelho carmim. A solução é composta de $1 \mathrm{~g}$ de fenolftaleína, $49 \mathrm{~g}$ de álcool e $50 \mathrm{~g}$ de água. Tendo como objetivo a determinação da profundidade de carbonatação in situ, esse estudo de caso teve como base a especificação portuguesa E391 do Laboratório Nacional de Engenharia Civil. Mede-se ao final do ensaio a profundidade carbonatada com um paquímetro, obtendo-se assim a profundidade carbonatada.

\section{Esclerometria}

O ensaio de esclerometria fornece dados referentes à dureza superficial do concreto, um meio de determinar a qualidade da peça de concreto. Todo o processo é normatizado pela NBR 7584/2012, e como se trata de um ensaio não-destrutivo, não proporcionará dano à estrutura, podendo também ser realizado com a mesma em uso. Para realização do ensaio deve se evitar superfícies irregulares, ásperas, curvas ou talhadas, pois pode não obter valores homogêneos. Deverão ser evitadas também superfícies úmidas ou carbonatadas.

A área de ensaio deve ser preparada por meio do disco de carborundum em movimentos circulares, retirando toda poeira e pó superficial ali existente, para que não reste nenhum resíduo. Após isso, localiza o gabarito na superfície do pilar de uma área no mínimo $90 \mathrm{~cm}^{2}$ e no máximo $400 \mathrm{~cm}^{2}$, riscando com um pincel. Em seguida, aplica-se o esclerômetro em todos os pontos marcados pelo pincel, obtendo os índices esclerométricos do gabarito.

Foi realizado o ensaio nos quatros pilares que existem na estrutura, seguindo algumas recomendações técnicas para se efetuar o ensaio: Evitar leituras menores que a $5 \mathrm{~cm}$ das arestas; Efetuar no mínimo 16 leituras; Não realizar mais de 1 impacto no mesmo ponto; Usar distância de no mínimo $3 \mathrm{~cm}$ entre os centros de dois pontos de impactos; Idade do concreto Ideal = 28 dias; Deve evitar impactos sobre armaduras, bolhas e áreas similares. A Figura 7 mostra o esclerômetro de reflexão utilizado no ensaio.

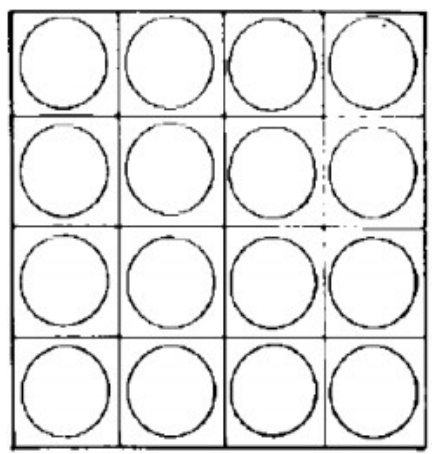

Figura 6: Esquema utilizado para realização do ensaio esclerométrico com 16 impactos. Fonte: NBR 7584 (2012). 


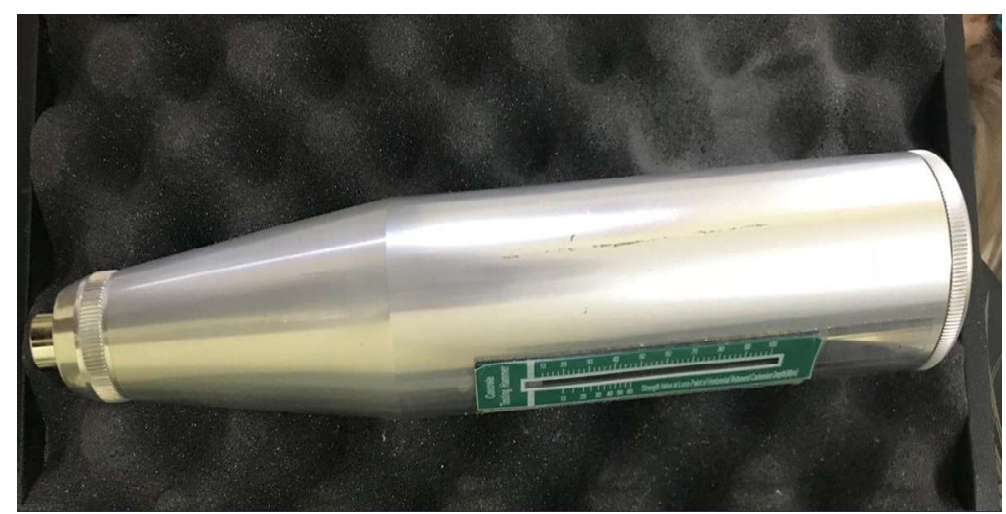

Figura 7: Esclerômetro de reflexão.

\section{RESULTADOS E DISCUSSÃO}

\section{Manifestações patológicas}

Diante da inspeção visual realizada na ponte, poucos problemas foram identificados, indicando uma ponte bem conservada. Foram utilizadas pedras juntamente com argamassa, para fazer acabamento da passagem do tubo da estação de água da cidade; EPS utilizado como aparelho de apoio, prática comum na época de construção; Devido à variação de nível da água, ocorreu a lixiviação da pasta nos pés dos pilares;

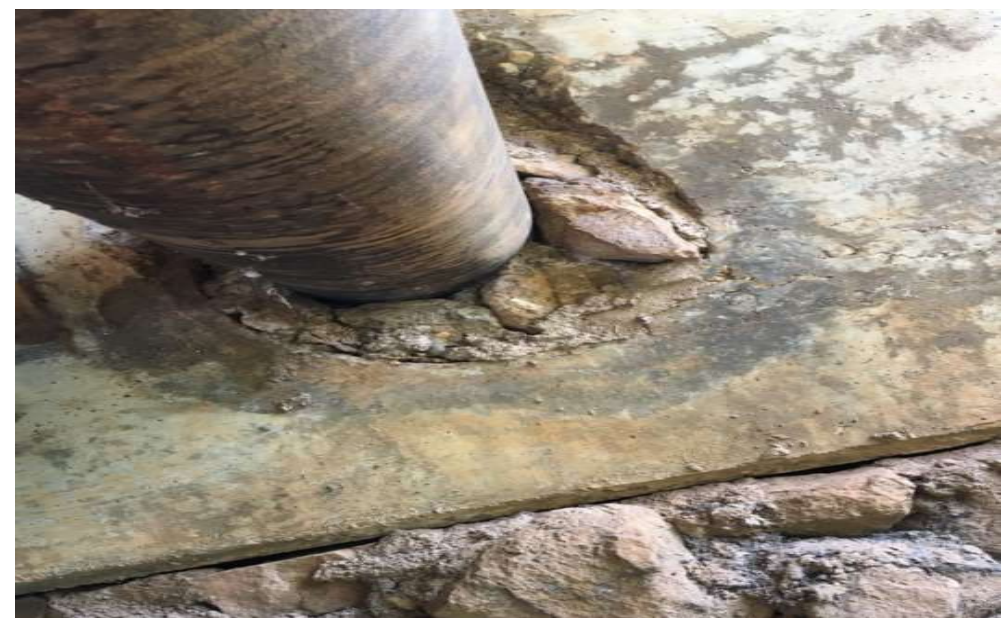

Figura 8: Pedra Aparente na Superfície.

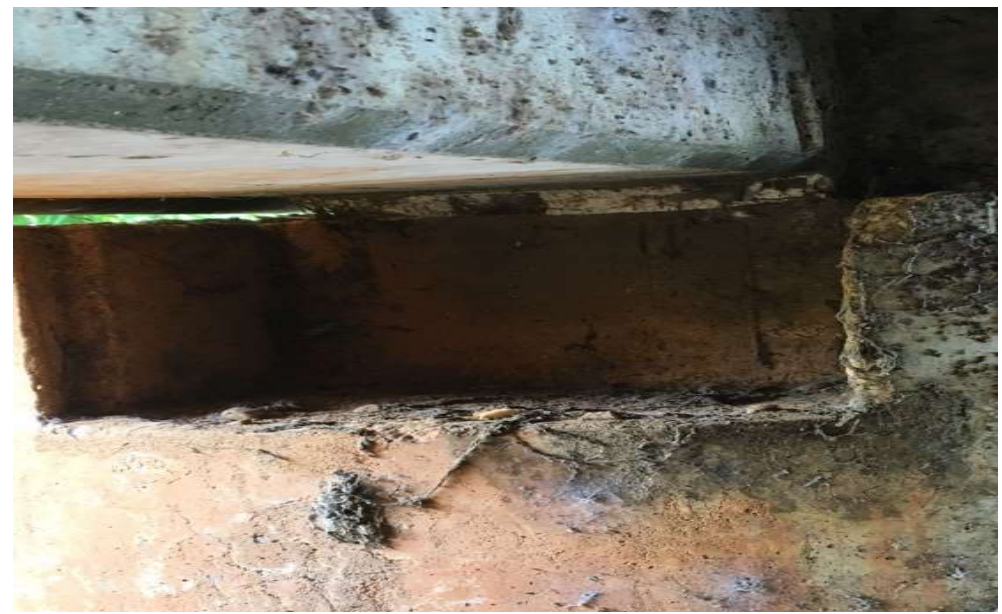

Figura 9: EPS usado como apoio. 


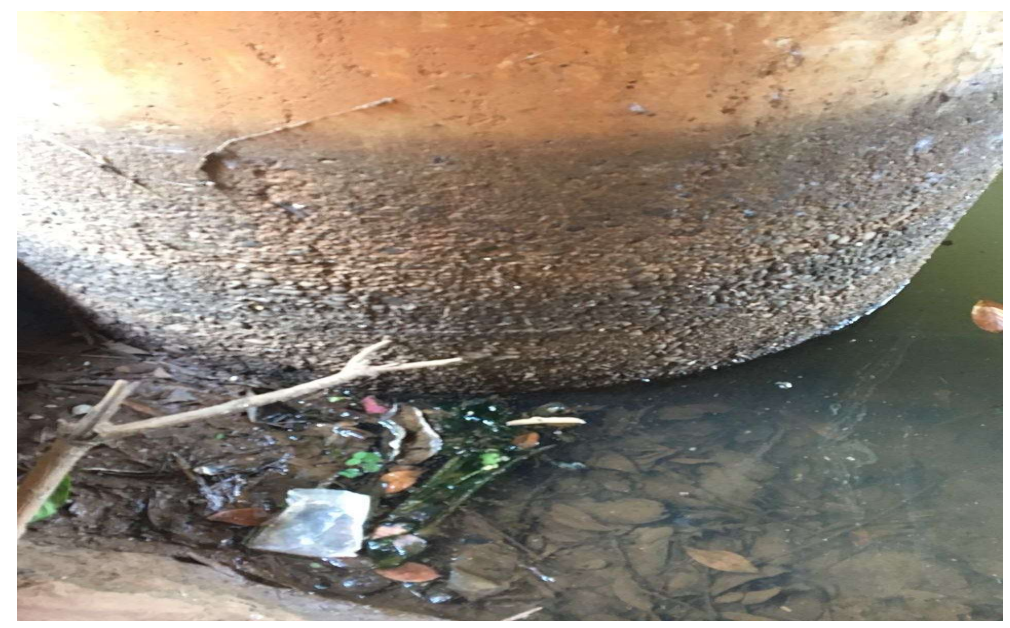

Figura 10: Lixiviação no Pilar.

\section{Ensaio de esclerometria}

O esclerômetro foi aplicado no sentido horizontal e antes de levá-lo a ponte, ele foi devidamente calibrado no Laboratório de Materiais da ITPAC Porto. Todos os dados foram registrados 'in loco' em uma planilha para depois serem analisados.

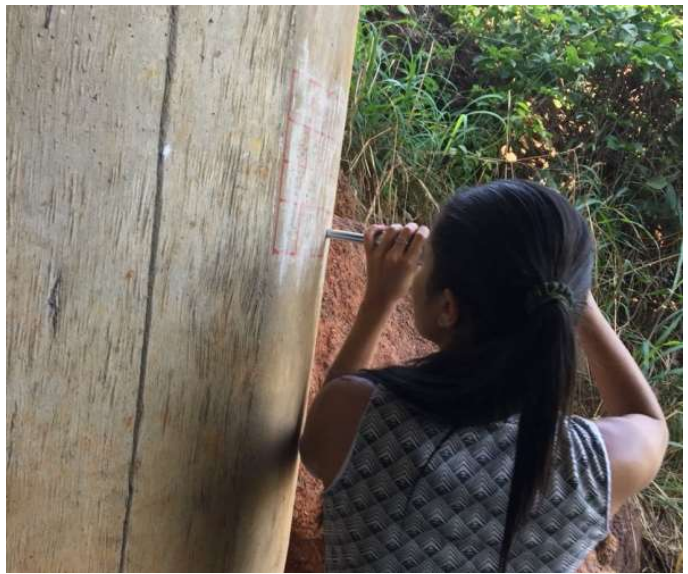

Figura 11: Realizando o ensaio.

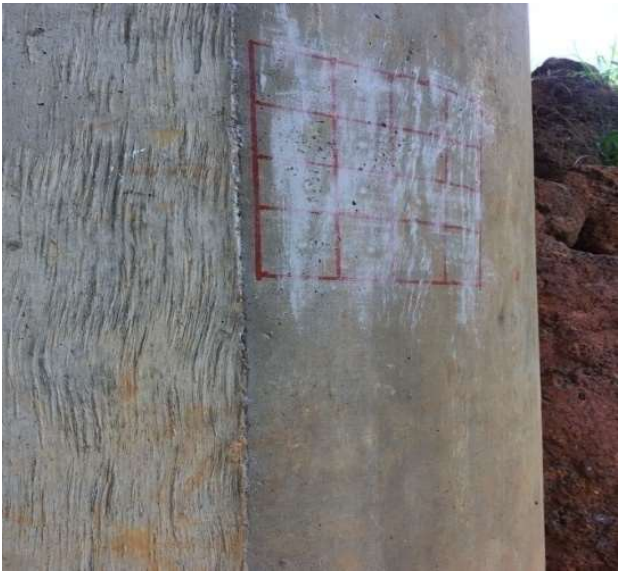

Figura 12: Gabarito no Pilar.

A superfície dos pilares apresentou ser plana devido ao elevado perímetro dos pilares circulares e adequada para o ensaio, assim como estavam secas e limpas, aumentando a precisão dos resultados. 0 Quadro 1 a seguir mostra os índices esclerométrico (I.E.), obtidos no aparelho na aplicação dos pontos realizados nos pilares.

Quadro 1: Quadro de Esclerometria.

\begin{tabular}{|l|l|l|l|l|l|l|l|l|l|l|l|l|l|l|l|l|}
\hline PILARES & \multicolumn{1}{l|}{ PONTOS } \\
\hline PILAR 1 & 1 & 2 & 3 & 4 & 5 & 6 & 7 & 8 & 9 & 10 & 11 & 12 & 13 & 14 & 15 & 16 \\
\hline I.E & 24 & $25^{*}$ & 15 & $28^{*}$ & $28^{*}$ & 36 & 16 & 18 & $30^{*}$ & 38 & 20 & $28^{*}$ & $30^{*}$ & 37 & 32 & $30^{*}$ \\
\hline PILAR 2 & 1 & 2 & 3 & 4 & 5 & 6 & 7 & 8 & 9 & 10 & 11 & 12 & 13 & 14 & 15 & 16 \\
\hline I.E & $31^{*}$ & $29^{*}$ & $29^{*}$ & $30^{*}$ & $32^{*}$ & $31^{*}$ & $28^{*}$ & $29^{*}$ & $31^{*}$ & $30^{*}$ & $31^{*}$ & 38 & $29^{*}$ & $27^{*}$ & 35 & $34^{*}$ \\
\hline PILAR 3 & 1 & 2 & 3 & 4 & 5 & 6 & 7 & 8 & 9 & 10 & 11 & 12 & 13 & 14 & 15 & 16 \\
\hline I.E & 21 & $30^{*}$ & $26^{*}$ & 21 & 36 & 36 & 35 & 38 & 32 & 35 & $29^{*}$ & $34^{*}$ & $30^{*}$ & $34^{*}$ & $32^{*}$ & $28^{*}$ \\
\hline PILAR 4 & 1 & 2 & 29 & 4 & 5 & 6 & 7 & 8 & 9 & 10 & 11 & 12 & 13 & 14 & 15 & 16 \\
\hline I.E & 27 & $32^{*}$ & $29^{*}$ & $31^{*}$ & 35 & 39 & $29^{*}$ & 14 & 37 & 39 & $32^{*}$ & $33^{*}$ & $32^{*}$ & $33^{*}$ & $29^{*}$ & $30^{*}$ \\
\hline
\end{tabular}


Os valores que estão com um 'asterisco' representam os que estão dentro da tolerância de +/- 10\% da média total do grupo inteiro. Para se obter a resistência dos pilares (Mpa), foi utilizado o ábaco esclerométrico (Gráfico 1). Para detalhar melhor esse estudo de caso, será feito a média do índice esclerométrico de cada pilar, individualmente, mais detalhado no Quadro 2.

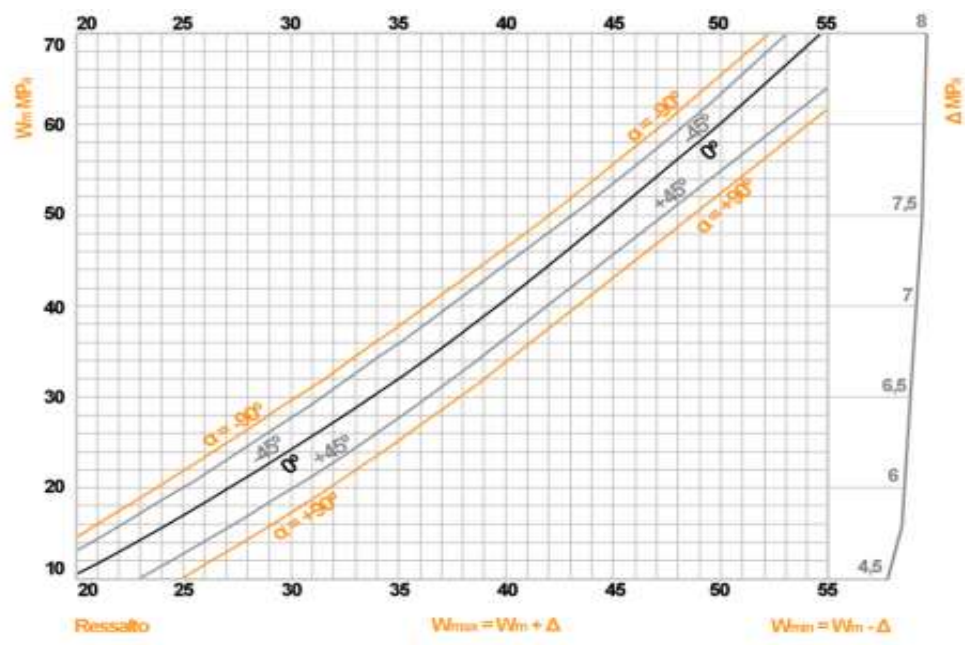

Gráfico 1: Ábaco da obtenção do índice esclerométrico.

Quadro 2: Resistência Obtida por pilar.

\begin{tabular}{|l|l|l|l|l|}
\hline PILARES & $\mathbf{1}$ & $\mathbf{2}$ & $\mathbf{3}$ & $\mathbf{4}$ \\
\hline SOMA & 435 & 494 & 497 & 501 \\
\hline MÉDIA & 27,19 & 30,88 & 31,06 & 31,31 \\
\hline $\mathbf{- 1 0} \%$ & 24,47 & 27,79 & 27,96 & 28,18 \\
\hline $\mathbf{1 0} \%$ & 30 & 34 & 34,17 & 34,44 \\
\hline FATOR DE CORREÇÃO & 0,94 & 0,94 & 0,94 & 0,94 \\
\hline ÍNDICE CORRIGIDO & 25,55 & 29,03 & 29,2 & 29,43 \\
\hline RESISTÊNCIA OBTIDA (MPa) & $\mathbf{2 1}$ & $\mathbf{2 7}$ & $\mathbf{2 7 , 4}$ & $\mathbf{2 7 , 7 5}$ \\
\hline
\end{tabular}

Medição da profundidade de carbonatação

Foram medidas as profundidades de carbonatação e cobrimento do concreto em todos os pilares (Quadro 3). Dentre os pilares a maior profundidade carbonatada encontrada foi de 23,75 mm no pilar 3, valor este que será usado para a correção do índice esclerométrico, uma vez que a carbonatação influencia os resultados da resistência superficial pelo I.E., com a introdução do $\mathrm{CO}_{2}$ para o interior do concreto, ocorre a formação de carbonato de cálcio nos poros, o que densifica a superfície do concreto, interferindo na reflexão do esclerômetro.

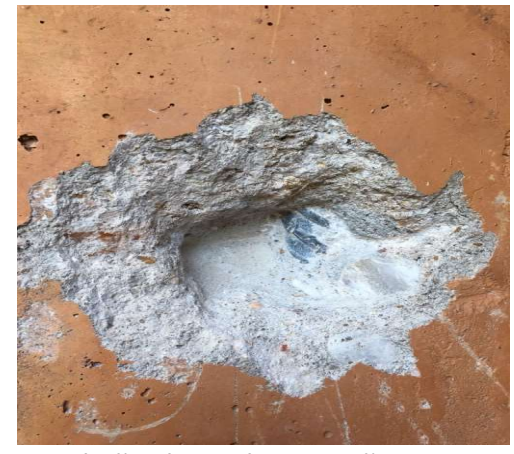

Figura 13: Medição da Carbonatação.

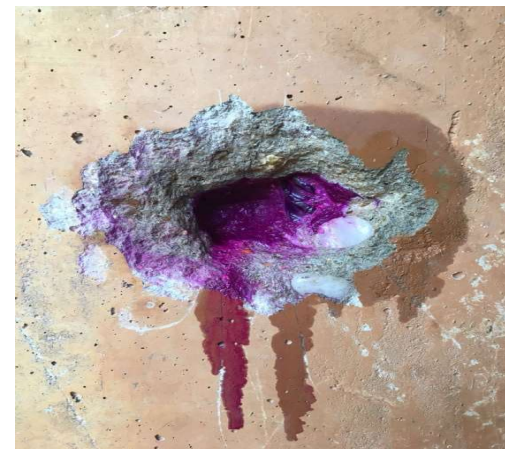

Figura 14: Medição da Carbonatação. 
Quadro 3: Profundidade de Carbonatação e Cobrimento do Concreto.

\begin{tabular}{|l|l|l|}
\hline PILARES & PROFUNDIDADE $(\mathrm{mm})$ & COBRIMENTO (mm) \\
\hline 1 & 16,35 & 40 \\
\hline 2 & 20,25 & 30 \\
\hline 3 & 23,75 & 40 \\
\hline 4 & 18,25 & 40 \\
\hline
\end{tabular}

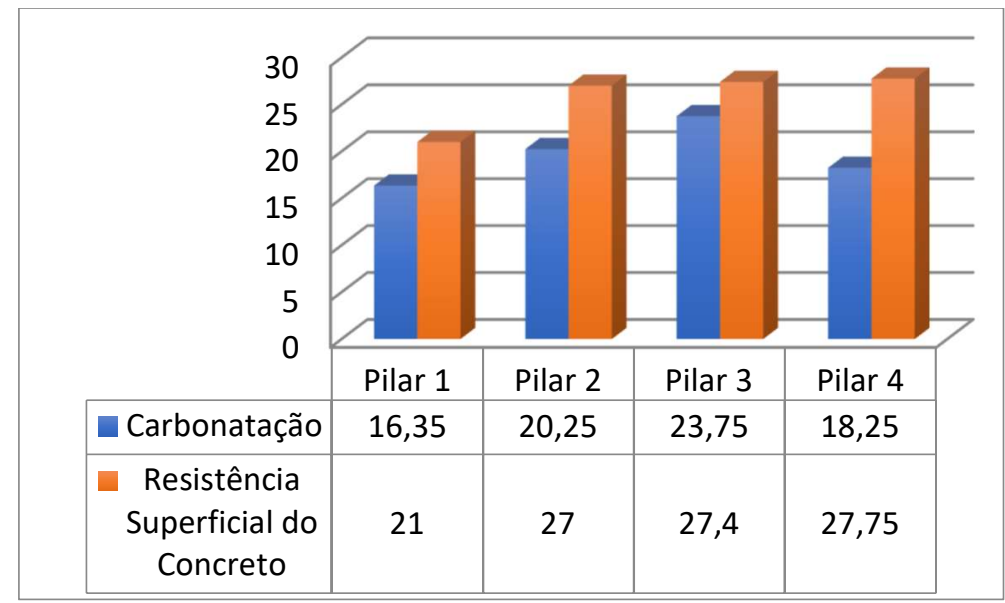

Gráfico 2: Gráfico Profundidade/Resistência Superficial do Concreto.

O gráfico da Gráfico 2 mostra a correlação entre os dois ensaios realizados. Observa-se que os pilares 2 e 3 tem uma profundidade carbonatada maior do que os pilares 1 e 4 . Podemos observar também que nenhuma frente de carbonatação chegou até as armaduras. No entanto, se torna interessante acompanhar nos próximos anos a evolução desse processo de carbonatação, uma vez que, apesar da velocidade de difusão do $\mathrm{CO}_{2}$ diminuir com o tempo em função da densificação dos poros, a camada de proteção medida nos pilares é apenas de 1 a $2 \mathrm{~cm}$. Já em relação à dureza superficial, temos maiores valores para os pilares 2 , 3 e 4, onde a literatura afirma que o índice esclerométrico aumenta de acordo com aumento da profundidade de carbonatação.

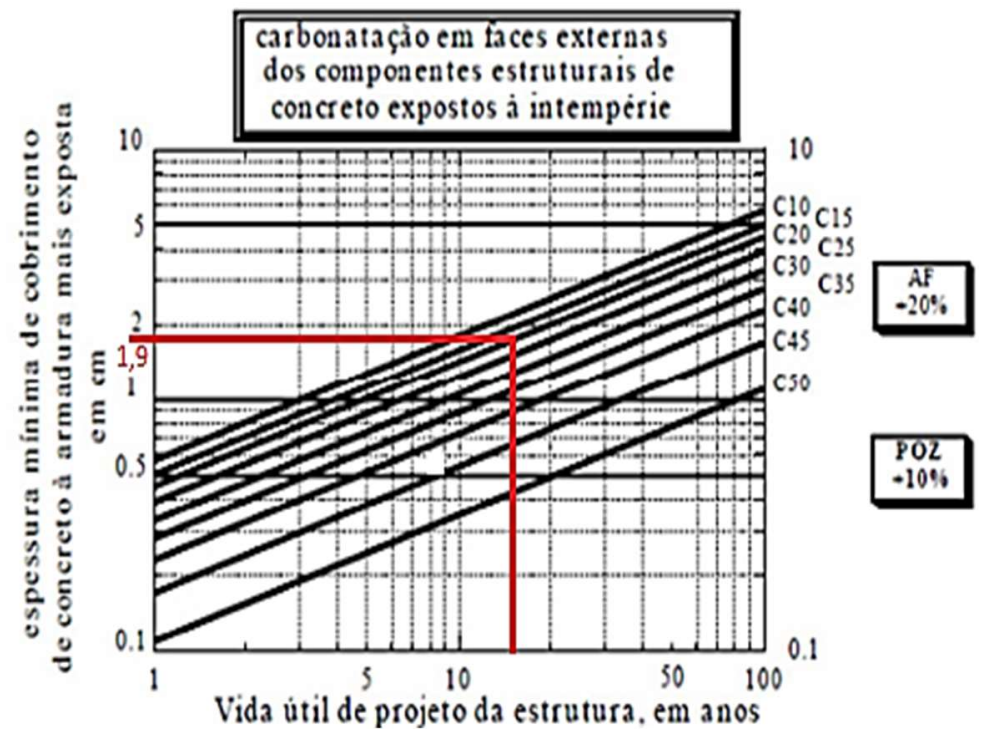

Figura 15: Carbonatação/tempo/fcd. Fonte: Helene (1997).

Utilizando o modelo de Helene (1997) para a evolução da carbonatação, que correlaciona a espessura de cobrimento com a resistência à compressão do concreto, foi possível estimar o restante da vida útil da estrutura, permitindo prever a necessidade futura de intervenções. Conforme ilustrado na Figura 15, 
considerando que o concreto utilizado teria um fcd mínimo de $20 \mathrm{Mpa}$ (limite comum na época de construção), e que a ponte apresenta uma idade de 16 anos, ao levarmos em conta uma espessura média de cobrimento de $1,9 \mathrm{~cm}$ ainda presente nos pilares, estima-se que os pilares da ponte ainda possuem uma vida útil próxima de 15 anos, vindo a necessitar de reparos após esse período com a perda da camada de proteção das armaduras.

\section{CONCLUSÕES}

No presente trabalho, foram realizados ensaios para avaliar a carbonatação na ponte ligando o setor Umuarama e o Centro da cidade, localizada no município de Porto Nacional/TO. Observou-se algumas patologias, porém não foi realizado nenhum estudo mais aprofundado para averiguar os eventuais possíveis danos a estrutura futuramente.

Os pilares, em 16 anos, já perderam de 40,8\% a 67,5\% da espessura de suas camadas passivadoras. As elevadas profundidades de carbonatação encontradas e evidenciadas pelos resultados esclerométricos, podem ser atribuídas à elevada temperatura característica da região em que a ponte foi construída, à presença constante de umidade (presença de rio) e à elevada porosidade do concreto utilizado (20Mpa e $25 \mathrm{MPa}$ de resistência à compressão) comprometendo sua qualidade, fatores esses que podem ter comprometido a durabilidade da estrutura, que deveria atingir uma vida útil de projeto de 100 anos.

Os resultados encontrados serão encaminhados aos órgãos da municipalidade, cumprindo com o dever dos profissionais da engenharia de zelar pela segurança e contribuir com a comunidade. Fica a sugestão de realizar esse mesmo trabalho nas outras pontes na cidade e pesquisar se existe alguma correlação das elevadas profundidades de carbonatação possivelmente encontradas com a presença constante de queimadas na região, uma vez que o tráfego na cidade é leve, não justificando uma concentração elevada de $\mathrm{CO}_{2}$ nas proximidades dessas obras de arte.

AGRADECIMENTOS: Agradecimento aos meus amigos que voluntariamente disponibilizaram parte do seu tempo para a execução deste trabalho. Agradeço aos professores que sempre estiveram dispostos a ajudar e contribuir para um melhor aprendizado em especial a minha professora orientadora. Agradeço também ao laboratório de construção civil por ter me dado todas as ferramentas que permitiram chegar ao final desse ciclo de maneira satisfatória.

\section{REFERÊNCIAS}

ABNT. Associação brasileira de normas técnicas. NBR 5674/1999. Manutenção de Edificações: Procedimento. Rio de Janeiro, 1999.

ABNT. Associação brasileira de normas técnicas. NBR 7584/2012. Avaliação da dureza superficial pelo esclerômetro de reflexão: Método de Ensaio. Rio de Janeiro, 2012.
BERTOLLINI, L.. Materiais de Construção: Patologia, Reabilitação, Prevenção. São Paulo: Oficina de textos, 2010.

CASCUDO, O.; CARASEK, H.. Ação da carbonatação no concreto. In: ISAIA, G. E. Concreto: Ciência e Tecnologia. 1 ed. São Paulo: Instituto Brasileiro do Concreto, 2011. p.1984

HELENE, P.. Manutenção para Reparo, Reforço e Proteção de Estruturas de Concreto. 2 ed. São Paulo: Pini, 1997. 
MEHTA, P. K.; MONTEIRO, P. J. M.. Concreto:

microestrutura, propriedades e materiais. 3 ed. São Paulo:

IBRACON, 2008.

POSSAN, E.. Previsão de vida útil de estruturas de concreto armado: estudo do período de iniciação da corrosão desencadeada por carbonatação. Tese (Doutorado em
Engenharia Civil) - Universidade Federal do Rio Grande do Sul, Porto Alegre, 2009.

SILVA, E. M.. Manifestações Patológicas em Revestimentos: Análise e Terapia. Monografia (Bacharelado em Engenharia Civil) - Universidade Federal de Santa Maria, Rio Grande do Sul, 2016.

A CBPC - Companhia Brasileira de Produção Científica (CNPJ: 11.221.422/0001-03) detém os direitos materiais desta publicação. Os direitos referem-se à publicação do trabalho em qualquer parte do mundo, incluindo os direitos às renovações, expansões e disseminações da contribuição, bem como outros direitos subsidiários. Todos os trabalhos publicados eletronicamente poderão posteriormente ser publicados em coletâneas impressas sob coordenação da Sustenere Publishing, da Companhia Brasileira de Produção Científica e seus parceiros autorizados. Os (as) autores (as) preservam os direitos autorais, mas não têm permissão para a publicação da contribuição em outro meio, impresso ou digital, em português ou em tradução. 